\title{
ECOLOGICAL NICHE MODELING USING SATELLITE DATA FOR ASSESSING DISTRIBUTION OF THREATENED SPECIES CEROPEGIA BULBOSA ROXB.
}

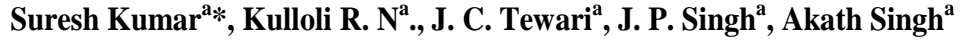 \\ ${ }^{a}$ Central Arid Zone Research Institute, \\ Jodhpur-342003, Rajasthan, India. \\ (sk_ecology@yahoo.co.in, r.kulloli@gmail.com, drjctewari@gmail.com, singh.akath@gmail.com, singh_jpbkn@yahoo.com)
}

KEYWORDS: Ceropegia bulbosa, Density, Endemic, GIS, Remote sensing

\begin{abstract}
:
Ceropegia bulbosa Roxb. is a narrow endemic, tuberous twiner of Asclepiadaceae family. It is medicinally important: tubers are nutritive and edible, leaves are digestive and a cure for dysentery and diarrhea. Exploitation for its tubers and poor regeneration of this species has shrunk its distribution. In order to know its present status, we report here the results of its appraisal in Rajasthan, using remote sensing and ground truthing in the past five years (2009-14). A base map of C. bulbosa was prepared using Geographical Information System (GIS), open source software Quantum GIS, SAGA. The Landsat Enhanced Thematic Mapper (ETM) +Advanced Spaceborne Thermal Emission and Reflection Radiometer (ASTER), Global Digital Elevation Model (GDEM) Satellite Data were used in this study. ASTER and GDEM Data was clipped with district boundary and provided color range to get elevation information. A digital elevation model of Rajasthan physiography was developed from ASTER GDEM of 30-m resolution. GIS layers of Area of occurrences for C. bulbosa plant and elevation were created. This map along with topographic sheets of 1:50000 were used for field traversing and ground truthing as per GPS location inferred from map. Its geographic distribution was assessed using MaxEnt distribution modelling algorithm that employed 12 presence locality data, 19 bioclimatic variables, and elevation data. Results of this modelling predicted occurrence of C. bulbosa in the districts of Sirohi, Jalore, Barmer, Pali, Ajmer, Jhalawar, Dungarpur, Banswara, Baran, Kota, Bundi and Chittorgarh. Ground validation in these districts revealed its presence only at four places in three districts confirming its rarity. Analysis of dominance at their sites of occurrence revealed their poor populations and sub dominant status (RIV=20-32) and very low density $(2-12$ plants per tenth ha).
\end{abstract}

*Corresponding author

\section{Introduction}

Prior knowledge of variety and variability in flora and fauna is essential for planning any conservation program (Lubchenco et al., 1991). This is essential in view of immense economic, ethical and aesthetical benefits of biodiversity besides its value in ecosystem function and stability (Tilman, 2000). Though various aspects of biodiversity are yet to be understood its accelerated loss is widely agreed, especially by habitat loss and fragmentation as well as by environmental degradation (Thomson et al., 2007).It is in this context that modern tools of GIS may be used to provide, handle and analyze spatial data sets needed to understand and prioritize a range of conservation and management tasks (Best et al., 2007). These tasks of conservation activities can be carried out using satellite data at a range of scales (Kiage et al., 2007).
Remotely sensed data in conjunction with geographic information systems have been successfully utilized to quantify biodiversity loss as well as its fragmentation (Jha et al., 2005). Numerous mathematical techniques have also been developed to predict the geographical distribution of given species (Soberon \& Peterson, 2005). Combined with GIS tools, the models generate maps of the habitats having similarity with those housing a particular threatened species. Among such models, MaxEnt (maximum entropy algorithm modeling programme) has been widely used in recent studies (Elith et al., 2006, Philips et al., 2006). Such attempts to map the spatial distribution of threatened plants of India at a sufficiently large scale with or without remote sensing are few (Yang, 2013; Adhikari et al., 2012; Barik \& Adhikari, 2011). We are not aware of any such study especially in respect of threatened plants of arid zone of India. It is in this context Ceropegia bulbosa Roxb. an endemic, 
rupicolous, bulbous arid species was taken in this study. It is medicinally important: tubers are nutritive and edible; leaves are digestive and a cure for dysentery and diarrhea. Its flowers are botanical marvels. Extraction of its tubers at accelerated pace in past quarter century coupled with poor regeneration has declined its density and shrunk its extent so much so that it now stands threatened. Knowing its extent and distribution shall inter-alia also help in locating potential areas of its distribution. Hence an attempt has been made here for Ecological Niche Modeling (ENM) using satellite data to assess population status of $C$. bulbosa in Rajasthan.

\section{Methodology}

\subsection{Study Area}

The study was carried out in Rajasthan state of India. Average annual rainfall shows a gradient of $200 \mathrm{~mm}$ in Jaisalmer in the west to $550 \mathrm{~mm}$ in Sirohi in the east.Rains are erratic, uneven and variable across the year; coefficient of variability being over 55\%. Extremes of temperatures like $50{ }^{\circ} \mathrm{C}$ in summer and $-2{ }^{\circ} \mathrm{C}$ in winters results in hot winds and frosts, respectively. High wind speed (20-40 $\mathrm{km} / \mathrm{hr}$ ), high evapotranspiration (1500-2000 mm/ year), poor soil fertility, low water retention capacity as well as deep brackish ground water make plant survival and growth very difficult (CAZRI, 2007). Consequently , arid landscape has poor tree cover and dominance of sparsely located shrubs. Some $6.4 \%$ of plant species of a total of 682 species in Indian arid zone are endemic. One such species is Ceropegia bulbosa Roxb. of family Asclepiadaceae. Occurrence records of $C$. bulbosa collected from previously published research papers, floras and herbarium revealed its reported occurrence on hilly areas in high rainfall receiving, wetter margin of arid Rajasthan.

\subsection{Satellite data}

The Landsat ETM+ and ASTER GDEM Satellite Data were used in this study. ERDAS Imagine 9.1 and Arc GIS 9.2 software were used for digital image processing and spatial database handling respectively. Aster GDEM Data with District boundary was clipped. A digital elevation model of Rajasthan physiography was developed from ASTER (Advanced Spaceborne Thermal Emission and Reflection Radiometer) GDEM (Global Digital Elevation Model) Data of 30-m resolution. GIS layers of area of occurrences for Ceropegia plant and elevation were created. This map along with Survey of India (S.O.I) topographic sheets of 1:50000 were used for field traversing and ground truthing as per GPS location.

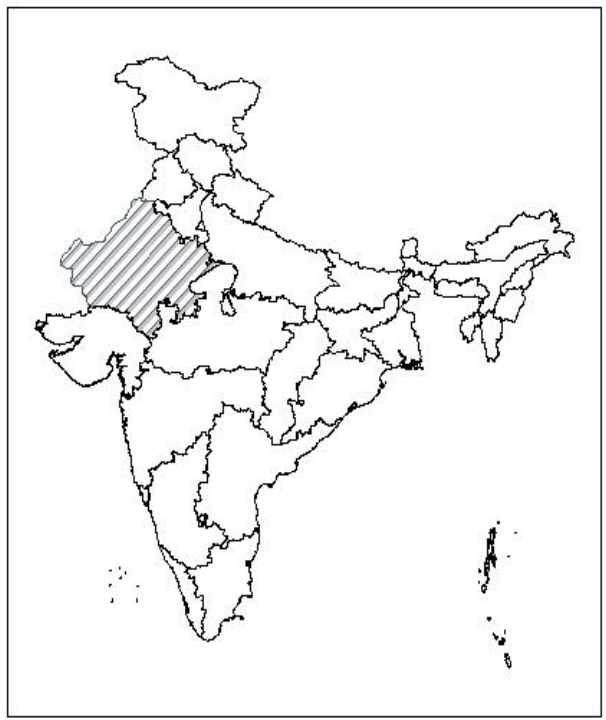

Figure 1. Study area of Ceropegia bulbosa in Rajasthan.

\subsection{MaxEnt model}

MaxEnt is a general purpose model that assesses environmental layers based on the training data location and then selects the probability of occurrence of species in the whole study area (Buehler \& Ungar, 2001). It is based on maximum entropy algorithm and can be downloaded from the website: http://www.cs.princeton.edu/ schapire/maxent/ (Phillips et al., 2006). This was employed in the present study.

\subsection{Environmental variables}

Two types of environmental variables viz. bioclimatic variables and elevation were used in this study (Table 1). Nineteen bioclimatic variables (Hijmans et al., 2005) with 1 $\mathrm{km}$ resolution, were downloaded from World climate 
website (http://www.worldclim.org.). This has a set of climate layers representing bioclimatic variables, derived from monthly temperatures and rainfall recorded worldwide (Graham \& Hijmans, 2006). The multicollinearity test was conducted by using Pearson Correlation Coefficient to examine the cross-correlation. The variables with cross- correlation coefficient value of over 0.8 were excluded. Elevation (Digital Elevation Model-DEM) data were also obtained from the WorldClim website. All these variables are taken from mean value over 10 years from 2003 to 2013. Presence data of 12 sites was used in modeling. The prediction year was 2013.

\subsection{Modeling Procedure}

C. bulbosa occurrence point data was divided into training data $75 \%$ of occurrence point data used for model prediction) and test data (25\% occurrence point data used for model validation). Then we evaluated the resulting model with the Receiver Operating Curves (ROC) calculating the area under curve (AUC). Higher AUC score indicates better prediction by model regarding species presence/absence. It also indicated those environmental variables that are highly correlated with the predicted distribution of species. The AUC values of $0.8-0.9$ or 0.9 1.0 show good or excellent predictions respectively (Swets, 1988).

\begin{tabular}{|l|l|l|l|l|l|l|l|}
\hline $\begin{array}{l}\text { Sr. } \\
\text { No. }\end{array}$ & Code & Variable & Unit & $\begin{array}{l}\text { Sr. } \\
\text { No. }\end{array}$ & Code & Variable & $\begin{array}{l}\text { Uni } \\
\mathbf{t}\end{array}$ \\
\hline 1 & Bio_1 & Annual Mean Temp. & ${ }^{0} \mathrm{C}$ & 11 & Bio_11 & Mean Temp. of Coldest Quarter & ${ }^{0} \mathrm{C}$ \\
\hline 2 & Bio_2 & Mean Diurnal Range & ${ }^{0} \mathrm{C}$ & 12 & Bio_12 & Annual Precipitation & $\mathrm{mm}$ \\
\hline 3 & Bio_3 & Isothermality (Bio2/Bio7)*100 & - & 13 & Bio_13 & Precipitation of Wettest Month & $\mathrm{mm}$ \\
\hline 4 & Bio_4 & $\begin{array}{l}\text { Temp. Seasonality (Std. } \\
\text { deviation*100) }\end{array}$ & - & 14 & Bio_14 & Precipitation of Driest Month & $\mathrm{mm}$ \\
\hline 5 & Bio_5 & Max Temp. of Warmest Month & ${ }^{0} \mathrm{C}$ & 15 & Bio_15 & $\begin{array}{l}\text { Precipitation Seasonality } \\
\text { (Coefficient of variation) }\end{array}$ & - \\
\hline 6 & Bio_6 & Min Temp. of Warmest Month & ${ }^{0} \mathrm{C}$ & 16 & Bio_16 & Precipitation of Wettest Quarter & mm \\
\hline 7 & Bio_8 & Mean Temp. of Wettest Quarter & ${ }^{0} \mathrm{C}$ & 17 & Bio_17 & Precipitation of Driest Quarter & $\mathrm{mm}$ \\
\hline 8 & Bio_7 & Temp. Annual Range (Bio5-Bio6) & ${ }^{0} \mathrm{C}$ & 18 & Bio_18 & $\begin{array}{l}\text { Precipitation of Warmest } \\
\text { Quarter }\end{array}$ & $\mathrm{mm}$ \\
\hline 9 & Bio_9 & Mean Temp. of Driest Quarter & ${ }^{0} \mathrm{C}$ & 19 & Bio_19 & Precipitation of Coldest Quarter & $\mathrm{mm}$ \\
\hline 10 & Bio & Mean Temp. of Warmest Quarter & ${ }^{0} \mathrm{C}$ & 20 & h_DEM & Elevation & $\mathrm{m}$ \\
\hline
\end{tabular}

Table 1. List of Bioclimatic variables and elevation used in the model (Hijmans et al., 2005)

\subsection{Field sampling and data analysis}

Using locations inferred from DEM map, and potential area predicted by model were visited for ground truthing. Those having absence of Ceropegia were recorded accordingly. Those sites having Ceropegia were sampled in 5 to 10 quadrats of $10 \mathrm{~m} \mathrm{X} 10 \mathrm{~m}$ placed beside each other. Presence and density of Ceropegia and all associated species were recorded. The vegetation data were quantitatively analyzed for frequency, density and dominance and relativized following Misra (1968). Dominant, co-dominant and main associate species based on RIV (Relative Importance Value) were recognized (Muller-Dombois \& Ellenberg, 1974).

\section{Results and Discussion}

\subsection{MaxEnt Modeling Analysis}

Regions of occurrence of $C$. bulbosa predicted by MaxEnt model are shown in figure 2. Statistical evaluation of the MaxEnt model indicated that the model provided useful prediction. The AUC was above 0.9 for all variables indicating very high accuracy (Swets, 1988). The model that included all variables had the highest AUC. Relatively high AUC values (>0.8) for the testing points, were another 
indication of the predictive power of the model. Finally, MaxEnt tests the null hypothesis that the test points are predicting no better than a random prediction using various thresholds (Phillips et al. 2006). Further the MaxEnt model also allows for performing an internal jack-knife test to quantify the importance of the variables in influencing the distribution of C. bulbosa (Fig. 3).

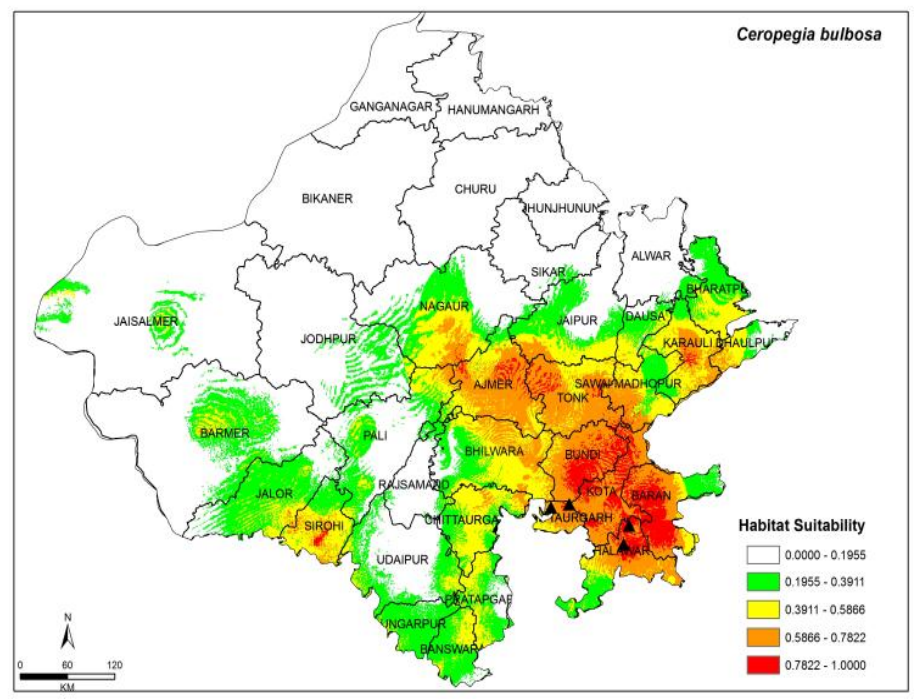

Figure 2. Predicted potential distribution of C. bulbosa in Rajasthan.

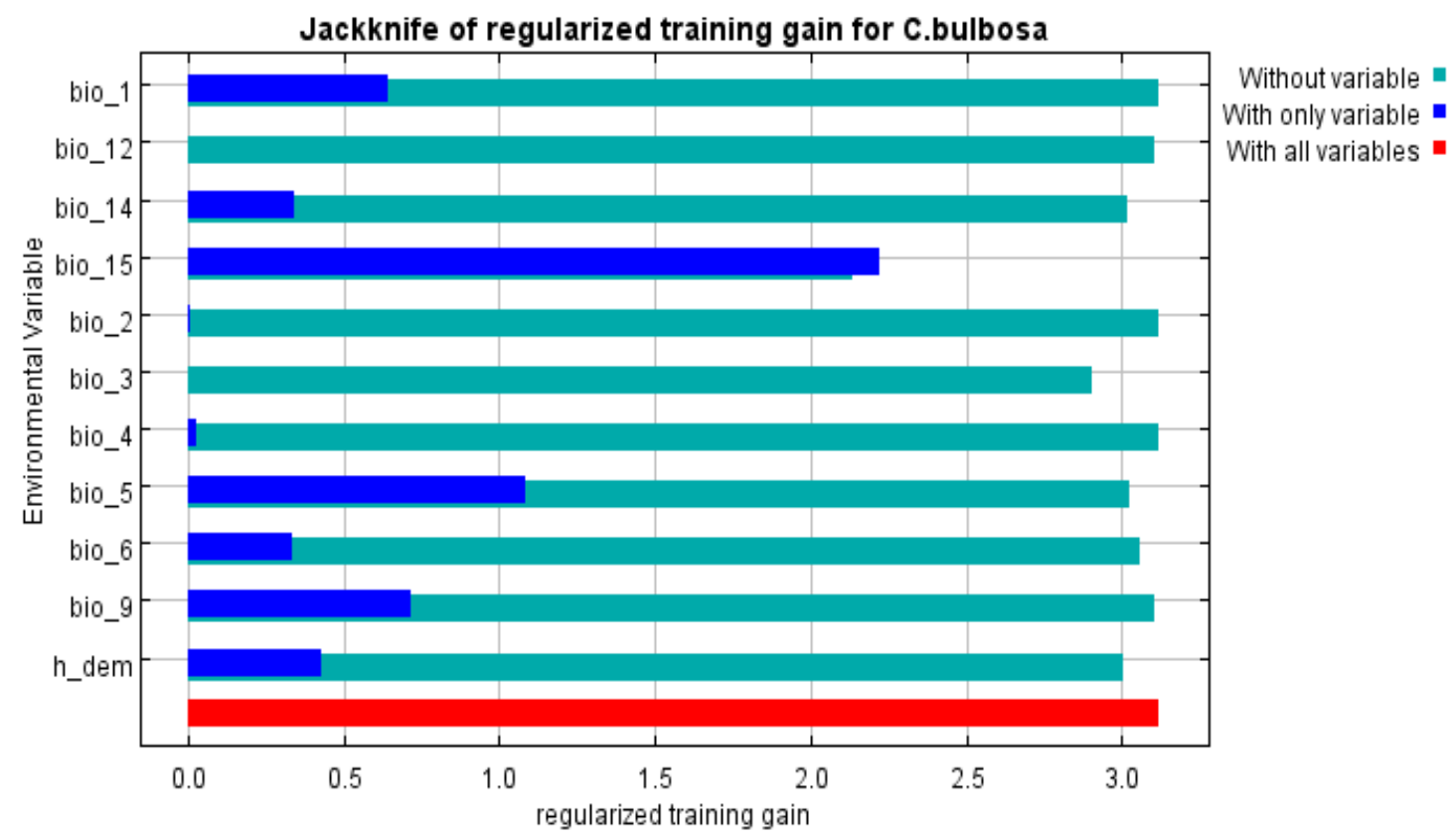

Figure 3. Results of Jackknife evaluations of relative importance of predictor variables for C. bulbosa Maxent model.

\subsection{Contribution of the variables to the model}

Variables like precipitation of wettest quarter (Bio-15), maximum temperature of warmest month (Bio-5) and Isothermality (Bio-3) contributed most to the model. Their individual contribution was $69.9 \%, 9.7 \%$ and $3.3 \%$ respectively. Elevation (h-DEM) has contributed only $2.5 \%$

(Table 2). 


\begin{tabular}{|l|l|l|}
\hline Variable & $\begin{array}{l}\text { Percent } \\
\text { contribution }\end{array}$ & Source/Reference \\
\hline Bio-15 & 69.9 & WorldClim; Hijmans et al., 2005 \\
\hline Bio-5 & 9.7 & WorldClim; Hijmans et al., 2005 \\
\hline Bio-3 & 7.7 & WorldClim; Hijmans et al., 2005 \\
\hline Bio-1 & 3.3 & WorldClim; Hijmans et al., 2005 \\
\hline h-DEM & 2.5 & Generated in GIS \\
\hline Bio-14 & 2 & WorldClim; Hijmans et al., 2005 \\
\hline Bio-12 & 2 & WorldClim; Hijmans et al., 2005 \\
\hline Bio-6 & 1.8 & WorldClim; Hijmans et al., 2005 \\
\hline Bio-9 & 1.3 & WorldClim; Hijmans et al., 2005 \\
\hline Bio-2 & 0 & WorldClim; Hijmans et al., 2005 \\
\hline Bio-4 & 0 & WorldClim; Hijmans et al., 2005 \\
\hline
\end{tabular}

Table 2. Relative contribution of variables to the MaxEnt Model.

\subsection{Ground truthing}

A perusal of Fig 2 revealed that MaxEnt modeling predicted occurrence of $C$. bulbosa in the districts of Sirohi, Jalore, Barmer, Pali, Ajmer, Jhalawar, Dungarpur, Banswara, Baran, Kota, Bundi and Chittorgarh. Survey of predicted region revealed that it was not found in eight out of twelve districts. Four districts recording its presence are Jalore, Baran, Jhalawar and Chittorgarh, wherein it was present at eight sites (Table 3). It occurred at sites having altitude of $846 \mathrm{ft}$ to $1849 \mathrm{~m}$, thus preferring hills. Its habitat had loamy soils. Most common associates included Capparis decidua, Prosopis juliflora, Butea monosperma, Anogeissus pendula, Ziziphus nummularia, Capparis sepiaria, Acacia leucophloea, and Maytenus emarginata. Its density was low, 2-12 plants per tenth ha while ecologically it was subdominant at all sites (Table 3 ). Of its earlier reported occurrences at Jhunjhunun and Jodhpur it has not been found, mainly because of large scale degradation of habitat due to mining, habitat fragmentation and extraction of its bulbs. These are also the reasons for its absence in other eight districts. Many researchers using MaxEnt modeling have reported that potential distribution areas predicted by model was almost always overestimated compared to realized niche of the species (Yang et al., 2013; Pearson, 2007; Murienne et al., 2009; Kumar \& Stohlgren, 2009). They ascribed it to the fact that niche based presence data in MaxEnt modeling results in predicting fundamental niche rather than realized niche and hence its absence in many (eight districts) of the predicted areas. Adverse anthropological factors stated earlier have further contributed to limiting its spread and distribution across districts; these insularised its populations. C. bulbosa has been recorded up to $\approx 1850 \mathrm{ft}$ elevations indicating that it is narrowly endemic. IrfanUllah et al., (2006), while mapping geographic distribution of Agalia bourdillonii using ENM in Western Ghats also concluded its narrowly endemic distribution that enabled them to identify key zones for additional protection. Narrowly endemic species have specific requirements which often make them vulnerable due to narrow ecological tolerances. That these environmental factors such as climate, geology and soil affect vegetation indices in time and space was also concluded by Soleimani et al., (2008). Precipitation of wettest quarter contributed maximum $(69.9 \%)$ to model prediction. Any decline in precipitation due to climatic change will make C. bulbosa increasingly vulnerable enhancing risk to its survival. Such estimates however need to be refined with finer scale climatic variables because bioclimatic variables based on interpolations of global climatic data have coarse resolution (Singh, 2013). 


\begin{tabular}{|l|l|c|c|}
\hline \multicolumn{1}{|c|}{ Site } & \multicolumn{1}{|c|}{ District } & $\begin{array}{c}\text { Density } \\
\text { per } \\
\text { tenth ha }\end{array}$ & RIV \\
\hline Manpura/Kharkhada & Baran & 8 & 32.42 \\
\hline $\begin{array}{l}\text { Brahmni Mata } \\
\text { Temple, Sorsan }\end{array}$ & Baran & 6 & 20.89 \\
\hline Sundha Mata hill & Jalore & 4 & 7.14 \\
\hline Jagannath Goshala & Jalore & 12 & 20.84 \\
\hline Ralawata, Khanpur & Jhalawar & 8 & 12.66 \\
\hline Chuna Bhatti-1 & Jhalawar & 6 & 12.66 \\
\hline Khumanganj, & Chittorgarh & 10 & 20.98 \\
\hline Bhaisrogarh & Chittorgarh & 2 & 10.63 \\
\hline
\end{tabular}

Table 3. Density and dominance of C. bulbosa found at different locations in Rajasthan.

\section{Conclusion}

It can be concluded that Maxent modeling has successfully predicted its occurrence even on the basis of limited data set. Precipitation of wettest quarter emerged as a major factor in determining the distribution of potential habitats of C. bulbosa in Rajasthan. Potential habitats of C. bulbosa are predicted in the districts of Baran, Jhalawar, Kota, Chittorgarh, Ajmer, Tonk and Sirohi, partially in Jalore, Sirohi, Nagaur and Karauli.

\section{Acknowledgments}

We are grateful to Director, CAZRI for providing necessary facilities for this work. The authors thank Department of Biotechnology, Govt. of India, New Delhi for financial support. Also we would like to thank Prof. S. K. Barik and Dr. Dibyendu Adhikari for necessary guidance in carrying out Ecological Niche Modeling.

\section{References}

Abbitt, R.J.F., Scott, J.M., Wilcove, D.S. 2000. The geography of vulnerability: incorporating species geography and human development patters into conservation planning. Biological Conservation 96: 169-175.

Adhikari, D., Barik, S.K., Upadhaya, K. 2012. Habitat distribution modelling for reintroduction of Ilex khasiana Purk., a critically endangered tree species of northeastern India. Ecological Engineering 40: 37-43.

Barik, S.K., Adhikari. D. 2011. Predicting geographic distribution of an invasive species Chromolaena odorata L (King) \& H. E. Robins in Indian subcontinent under climate change scenarios.
In: Bhatt, J.R., Singh, J.S., Tripathi, R.S., Singh, S.P., Kohli, R.K. (Eds.), Invasive Alien Plants- An Ecological Appraisal for the Indian Subcontinent. CABI, Oxfordshire, UK.

Best, B.D., Halpin, P.N., Fujioka, E., Read, A.J., Qian, S.S., Hazen, L.J. and Schick, R.S. 2007: Geospatial web services within a scientific workflow: predicting marine mammal habitats in a dynamic environment. Ecological Informatics. 2: 210-23.

Buehler, E.C., Ungar, L.H. 2001. Maximum Entropy Methods for Biological Sequence Modeling. BIOKDD 60-64.

CAZRI. 2007. CAZRI Perspective Plan: Vision-2025. Central Arid Zone Research Institute, Jodhpur, p. 94.

Elith, J., Graham, C.H., Anderson, R.P., Dudik, M., Ferrier, S., Guisan, A., Hijmans, R.J., Huettmann, F., Leathwick, J.R., Lehmann, A., Li, J., Lohmann, L.G., Loiselle, B.A., Manion, G., Moritz, C., Nakamura, M., Nakazawa, Y., Overton, J.M., Peterson, A.T., Phillips, S.J., Richardson, K., Scachetti-Pereira, R., Schapire, R.E., Soberón, J., Williams, S.E., Wisz, M.S., Zimmermann, N.E. 2006. Novel methods improve prediction of species' distributions from occurrence data. Ecography 29: 129-151.

Graham, C.H., Hijmans, R.J. 2006. A comparison of methods for mapping species ranges and species richness. Global Ecology and Biogeography 15: 578587.

Hijmans, R.J., Cameron, S.E., Parra, J.L., Jones, P.G., Jarvis, A. 2005. A very high resolution interpolated climate surface for global land areas. Int. J. Climatol. 25:1965-2198.

Irfan-Ullah, M., Amarnath, G., Murthy, M.S.R., Peterson, A.T. 2006. Mapping the geographic distribution of Aglaia bourdillonii Gamble (Meliaceae), an endemic and threatened plant, using ecological niche modeling. Biodiversity Conservation. 16: 1917-1925.

Jha, C.S., Goparaju, L., Tripathi, A., Gharai, B., Raghubanshi, A.S., Singh, J.S. 2005. Forest fragmentation and its impact on species diversity: an analysis using remote sensing and GIS. Biodiversity and Conservation. 14: 1681-1698.

Kiage, L.M., Liu, K.B., Walker, N.D., Lam, N., Huh, O.K. 2007: Recent land-cover/use change associated with land degradation in the Lake Baringo catchment, Kenya, East Africa: evidence from Landsat TM and ETM. International Journal of Remote Sensing. 28, 4285-309. 
Kumar, S., Stohlgren, T.J. 2009. Maxent modeling for predicting suitable habitat for threatened and endangered tree Canacomyrica monticola in New Caledonia. J. Ecol.. Nat. Envoron. 1:94-98.

Lubchenco, J., A.M. Olson, L.B. Brubaker, S.R. Carpenter, M.M. Holland, S.P. Hubbell, S.A. Levin, J.A. Macmahon, P.A. Matson, J.M. Melillo, H.A. Mooney, C.H. Peterson, H.R. Pulliam, L.A. Real, P.J. Regal \& P.G. Risser. 1991. The sustainable biosphere initiative: an ecological research agenda. Ecology 72: 371-412.

Misra, R. 1968. Ecology Work Book. pp. 235. Oxford and IBH Publishing Co., New Delhi.

Mueller-Dombois, D. Ellenberg, H. 1974. Aims and methods of vegetation ecology. pp. 525. John Wiley and Sons, New York.

Murienne, J., Gulbert, E., Grandcolas, P.. 2009. Species diversity in the New Caledonian endemic genera Cephalidiosus and Nobarnus Insecta: Heteroptera: Tingidae, an approach using phylogeny and species distribution modeling. Bot. J. Linn. Soc. 97:177-184.

Pearman, P.B., Penskar, M.R., Schools, E.H., Enander, H.D. 2000. Identifying potential indicators of conservation value using natural heritage occurrence data. Ecological Applications 16: 186201.

Pearson, R.G. 2007. Species distribution modelling for conservation educators and practitioners. Synthesis. American Museum of Natural History. http://ncep.amnh.org

Phillips, S.J., Anderson, R.P., Schapire, R.E. 2006. Maximum entropy modeling of species geographic distributions. Ecological Modeling. 190: 231-259.

Singh, M. 2013. Predictive modelling of the distribution of two critically endangered Dipterocarp trees: Implications for conservation of riparian forests in Borneo. J. Ecol.Nat.Enviro. 5(9): 254-259.

Soberon, J., Peterson, A.T. 2005. Interpretation of models of fundamental ecological niches and species distributional areas. Biodi. Info. 2:1-10.

Soleimani, K., Kordsavadkooh. T., Muosavi, S.R. 2008. The effect of environmental factors on vegetation changes using GIS (Case Study: Cherat Catchment, Iran). World Applied Science Journal. 3: 95-100.

Swets, J.A. 1988. Measuring the accuracy of diagnostic systems. Science. 240:1285-1293.
Thomson, A.G., Manchester, S.J., Swetnam, R.D., Smith, G.M., Wadsworth, R.A., Tilman, D. 2000. Causes, consequences and ethics of biodiversity. Nature. 405: 208-211.

Yang, X.Q., Sarah, S., Khushwaha, S.P.S., Xu, J. Roy, P.S. 2013. Maxent modeling for predicting the potential distribution of medicinal plant, Justicia adhatoda L. in Lesser Himalayan foothills. 51: 8387. 